\title{
Research of Blockchain and its Application in Accounting Recognition Based on Event Approach
}

\author{
Wenyao Zhou ${ }^{1, a, *}$, Quanfang Xiao ${ }^{2, b}$ \\ ${ }^{1}$ Wuhan Univ Technol, Sch Management, Wuhan 430000, Peoples R China \\ ${ }^{2}$ Wuhan Univ Technol, Sch Management, Wuhan 430000, Peoples R China \\ awyzhou929@163.com, bxqf1962@126.com
}

\begin{abstract}
Keywords: Accounting recognition, Block chain, Event approach accounting.
\end{abstract}
\begin{abstract}
As a new Internet technology, Block chain is highly concerned because of its unique advantages in distributed ledger. Based on the theory of event approach accounting, this paper subdivides the accounting recognition into two processes, and explores the application of the Block chain in the processes. With the application of Block chain, it is possible to make accounting recognition multidimensional and achieve the fundamental recognition criteria.
\end{abstract}

\section{Introduction}

The dimension of accounting recognition refers to the perspective of understanding, analyzing and describing the concept of accounting confirmation. The perspective can be multi-faceted, multi-level and multi-angle. However, the traditional accounting recognition system lacks the integrity and system of dimension, which makes the concept of accounting recognition narrow and the standard of accounting recognition flat. Event approach accounting provides another kind of accounting recognition, which makes the content of accounting recognition more abundant. Because of technical constraints, it was hard to carry out Event approach accounting. However, with the development of science and technology, Block chain has been maturing, so that the application of Event approach accounting is possible. At present, the study of the combination of Block chain and accounting has just started. Based on the Event approach accounting, This paper will explore how to combine the Block chain with accounting recognition..

\section{Definition of Accounting Recognition}

\subsection{General Definition of Accounting Recognition}

In 1922, W·A·Paton published "Accounting Theory". In the book, he mentioned "accounting recognition" regularly, but he did not give the specific definition of "accounting recognition". In December 1984, the Financial Accounting Standards Board(FASB) published the "Statement of Financial Accounting Concepts No. 5: Recognition and Measurement in Financial Statements of Business Enterprises " and indicated that " Recognition is the process of formally recording or incorporating an item in the financial statements of an entity as an asset, liability, revenue, expense, or the like. Recognition includes depiction of an item in both words and numbers, with the amount included in the totals of the financial statements." In other words, the accounting recognition includes two meanings: (a) the accountant determine whether some information should be recorded as an particular accounting element and how to measure this information. (b) The accountant determine the specific way to record this information in financial statements.

\subsection{Definition of Accounting Recognition in Event approach accounting}

In 1969, Professor George H. Sorter published a paper entitled "An Events Approach to Basic Accounting Theory ", and elaborated on the Event approach accounting. He regards the traditional accounting system as " value approach", which is based on the assumption that the user's needs for accounting information are known and can be described adequately and specifically, so that the optimal decision-making model can be inferred by accounting theory. On the contrary, the Event approach accounting is based on a completely different assumption that an accountant may know 
nothing about how the decision maker uses information and the accounting objective is to provide information about economic events for different possible decision-making models. Decision-related information should be kept in its original form as much as possible; accounts' task is to provide information about the events and so that the information users themselves process the required applicable information according to their needs to and use it in the decision-making model.

\subsection{Comparison between Two Definitions}

Compared with the general accounting recognition, there are a variety of measurement methods in Event approach accounting to reflect the various aspects of the event and reveal the value or nonvalue information of economic events and, so Event approach accounting has the features of comprehensiveness. Meanwhile, Event approach accounting provides authentic information so that different information users use different decision-making models to make decisions, and thus meet the needs of different information users.

Due to the technical limitations at the age of Sorter, the application of Event approach accounting lacks sufficient technical support and the information is difficult to record and extract comprehensively. Now with the development of Block chain technology, the application of Event approach accounting is possible.

\section{Block chain}

In 2008, a person called Satoshi Takemoto published "Bitcoin: a point-to-point electronic trading system", marking the birth of Bitcoin. In recent years, the world's attitude towards the Bitcoin mixed, but as one of the bottom technologies of Bitcoin, Block chain technology has been receiving attention.

\subsection{Essence of Block chain}

Block chain is a decentralized and distributed account database, like a database book, which records all the transaction records. Its essence is a string of data blocks generated by cryptography and each data block contains a number of valid transaction information. The information constitutes consists a main chain in chronological order. A block mainly includes transaction data of each side such as transaction keys, quantities and digital signatures. Each node calculated the random number competitively and the first node that gets the answer can generate a new block and broadcast to all nodes to update the transaction information.

\subsection{Features of Block chain}

(a) Decentralization

Because of the use of distributed accounting and storage, there is no centralized hardware or management organization, so the rights and obligations of any node are equal. The data blocks in the system are maintained by all the nodes with maintenance functions.

(b) Safety

The block chain takes the Message-Digest Algorithm 5, and each newly generated block is strictly advanced in chronological order. The irreversibility of time makes it easy to trace back any attempt to invade the data information in the Block chain and such attempt will be excluded by other nodes, thereby limiting the generation and execution of the illegal act.

At the same time, Block chain is distributed storage and all the information data carrier will be replaced by the network node. The information is recorded in the form of code and ledger. A node is updated, all nodes will record. In this way, even if information in one node is lost, it is possible to find backup copy from other nodes.

(c) Mutual verification

Since all transactions in the Block chain are to be broadcasted, other nodes will recognize the transaction contained in the latest block only if they are all unique. If some transaction data doesn't match most data in other nodes, the transaction will be denied. Therefore, even without a centralized institution, it is possible to prevent double payment effectively. 


\subsection{Application of Block chain}

Due to the above characteristics of, which satisfies the requirements of security and timeliness in the process of information processing at the Internet age, Block chain has attracted attention in all walks of life.

Melanie Swan, a philosophic and economic theorist of The New School for Social Research, points out in his book "Block chain: Blueprint for a new economy" that if the Block chain 1.0 refers to the currency, that is, the cash-related encrypted digital currency, such as currency, transfer, remittance and digital payment systems, then the Block chain 2.0 refers to a wider range of non-monetary applications such as stocks, bonds, futures, loans, smart assets and smart contracts. In the future Block chain may also evolve into the 3.0 stage, that is, Government, health, science, culture and art.

The R3 Consortium, established in 2015, which was dedicated to the application of Block chain in the finance field, has attracted more than 60 investment banks, including Goldman Sachs. In the accounting field, Deloitte and Ernst \& Young have set up Block chain research groups.

It is foreseeable that in the future, the Block chain technology will be widely used in the accounting work. With the help of Block chain technology, integrated accounting platform will be established. By interaction with the enterprise accounting system, the platform can complete the extraction of data automatically, and finished recognition, measurement, record and report of the accounting information in the meantime.

\section{Application of Block chain in accounting recognition}

\subsection{Subdivision of Accounting Recognition}

According to Event approach accounting, the first step of accounting recognition is logical judgments of economic events, that is extracting and recording the information of economic events as much as possible then generating economic essence; the second step is to transfer the recorded economic essence into accounting language and generate accounting information based on different accounting recognition basis and standards, such as debit and credit, accounting elements, value.

\subsection{Application of Block chain based on Subdivision of Accounting Recognition}

Based on the above subdivision process, Block chain can be divided into Event Block chain and Accounting Block chain. The Event Block chain deals with the process from economic event to economic essence; the Accounting Block chain deals with the process from economic essence to accounting information.

In the case of sales of goods, when the sales occurred, Event Block chain will record the number of goods, the quantity of good sold, the price of goods and cash payment records; in the Accounting Block chain, the system can calculate selling cost based on the number of goods sold and the cost of goods which is recorded in the previous Block chain. Based on the quantity of good sold and the price of goods, the system can calculate sales revenue. Based on the quantity and cost of goods sold and cash payment records, the system can calculate accounts receivable.

If someone attempts to extract false accounting information at the stage of Accounting Block chain, the act will be rejected by most of the blocks in the Event Block chain. Therefore, it is effective to ensure the validity of accounting recognition.

\subsection{Advantages of Application}

The above process not only meet fundamental recognition criteria, but also has some advantages:

(a) Combining Block chain technology and accounting recognition makes accounting recognition has features of decentralization and irreversibility, which meets the requirement of reliability;

(b) Block chain provides relatively integrated information and different users can extract the relevant information to recognize according to their own criteria, which meets the requirement of relevance;

(c) Using different accounting recognition standards lay a foundation of the multi-level financial statements. The standards of recognition in Accounting Block chain can be set liberally. Aiming at different objects, differentiated recognition standards can help to prepare a variety of different 
financial statements. Moreover, one object can be based on several different standards, so that the financial statements become much less hierarchical and have more comprehensive content.

\subsection{Challenges of Application}

Although the application of Block chain has many advantages, the real implement is still facing some challenges. First, Block chain needs fully consideration of a variety of situations in the process of data acquisition and comprehensive accounting standards planning. Secondly, the backup of and mutual verification need high-lever of hardware storage and computing power.

\section{Conclusion}

This paper subdivides the accounting recognition into two processes and combined with Event block chain and Accounting block chain, which can effectively improve the reliability and relevance of accounting recognition and lay the foundation of multi-level financial statements. Although the practical application of block chain is still faced with technical challenges, it can believe that in the future, block chain technology will make the accounting more effective, safe and comprehensive.

\section{References}

[1]. Financial Accounting Standards Board. Recognition and Measurement in Financial Statements of Business Enterprises. FASB Concepts Statement No.5, 1984.

[2]. G H Sorter. An events approach to basic accounting theory [J]. The Accounting Review,1969.

[3]. Zheng W. Defects and Improvements of Accounting Recognition Theory [J]. Accounting Research, 2015.

[4]. SATOSHI N. Bitcoin: A Peer- to- Peer Electronic Cash System [D]. Working Paper, 2008.

[5]. M Swan. Blockchain: Blueprint for a New Economy [M]. O'Reilly Media, 2015.

[6]. Zhong W, Jia Y Z. Prospect of the Application of Block Chain Technology in Accounting [J]. Friends of Accounting, 2016.

[7]. Tsai W T, B Robert, Yan Z, Lian Y. A System View of Financial Block chains [C]. IEEE, 2016. 